\section{Travel grants}

The International Federation of Parkinson's Disease Foundations, Inc announces that it will award travel grants to young investigators wishing to attend the 12th International Symposium on Parkinson's Disease to be held in London on 24-26 March 1997. To obtain such a grant, the individual should submit a one page application which includes present position, recent publications, and whether he will be presenting a paper or a poster at the meeting. A sponsoring letter from the chairman of the department or head of the laboratory in which the individual is presently working should be included. Send to: The International Federation of Parkinson's Disease Foundations, Inc.; 1200 Fifth Avenue, Apt 12-D; New York, New York 10029; Attention: Melvin D Yahr, MD.

\section{BOOK REVIEWS}

All titles reviewed here are available from the BMJ Bookshop, PO Box 295, London WC1H 9TE. Prices include postage in the United Kingdom and for members of the British Forces Overseas, but overseas customers should add $£ 2$ per item for postage and packing. Payment can be made by cheque in sterling drawn on a United Kingdom bank, or by credit card (Mastercard, Visa or American Express) stating card number, expiry date, and your full name.

Diffusion and Perfusion Magnetic Resonance Imaging: Applications to Functional MRI. Edited by DENIS LE BIHAN. (Pp 398; price \$183.00). Published by Raven Press, New York. 1995. ISBN 07817-0244-5.

This multiauthor book has a fifty-fifty contribution from physicians and scientists, predominantly physicists. Who is the book aimed at? On the one hand the book is too technical for radiologists and others in the medical profession, on the other the interpretation of the imaging data is clearly based on an expert knowledge of pathophysiology. In fact, I would be surprised if the majority of the authors of this book could verify the validity or otherwise of the many pages of mathematics, if called on to do so.

Diffusion imaging refers to an MR technique which uses the self diffusion of mole- cules to influence the tissue contrast of images and which can in principle be used to calculate the diffusion constants of a variety of molecules, usually water. Perfusion MR covers a variety of techniques, some of which provide maps of tissue microvascular perfusion as measured in physiology as well as other measures which have the appellation of perfusion but which are not directly related to physiological perfusion measures. The sections on perfusion methods extend to chapters on functional MR.

This book draws together the major workers in the field of this exacting magnetic resonance imaging technique. I enjoyed revisiting many images I had been familiar with when I had been involved in the field four years ago. Despite the passage of time an understanding of physiological basis of diffusion in imaging contrast is still as elusive as ever though debate is more sophisticated.

The strongest chapters are those dealing with physiological experimentation with animal models of human disease. Many of the chapters illustrating the effects in human subjects contain untestable statements, though that of course is in the nature of much of this type of research. The book would be a useful compendium for those active or about to embark on research in the field.

MARK DORAN

Peripheral Nerve Disorders 2. Edited by $A K$ ASBURY and $P$ K THOMAS. (Pp 316 ; $£ 45 \cdot 00$ ). Published by Butterworth Heinemann, Oxford 1995. ISBN 0-75061765-9.

The ground rules of the newly named "Blue Books of Practical Neurology" series from Butterworth Heinemann are crucial. Each volume is explicitly not intended as an inclusive text comprehensively covering the whole of the given field, rather it is a snap shot of individual areas within a subject in which significant "progress through research has brought about new concepts in patient management" (as the series editors point out) The choice of topics covered therefore becomes perhaps subjective but, while it is not difficult to suggest topics which might have been included in this excellent volume (no significant advances in the past decade in neuropathies associated with paraneoplasia or with diabetes?), it is very hard to suggest chapters which the current editors might have had omitted in order to allow additional inclusions.

There are outstanding reviews of inflammatory demyelination (Hughes), of infectious neuropathies related to borellia trypanosomiasis, and leprosy (Siede), and to
HIV (Cornblath and McArthur), and toxic and critical illness neuropathies (Shambury and Kaplan, and Bolton, respectively). The volume's editors have, however, loosely interpreting their brief, allowed one third or more of the monograph to comprise excellent practically-based chapters, including the clinical approach to neuropathy (Asbury and Thomas), mechanisms and treatment of positive motor (Thompson) and sensory (Ochoa) function and nerve biopsy (Thomas). These render this issue even more valuable than a series of authoritative and up to date reviews; it is thoroughly recommended.

NEIL SCOLDING

Introduction to Clinical Neurology. By DOUGLAS J GELB. (Pp 370; $£ 22.50)$ Published by Butterworth Heinemann, Oxford 1995. ISBN 0-7506-9651-6.

The difficulty most medical students have with neurology is learning how to pluck from the morass of detail in each history and examination the telling diagnostic features. The ability to weigh up contradictory signs and symptoms comes with experience, but traditional neurological teaching often does not help. For instance, how often have you taught the five distinguishing features of an upper or lower motor neuron lesion, when in fact a more honest summary of your own practice might be: "increased reflexes in a symptomatic limb suggest a central lesion; reduced reflexes in a symptomatic lesion suggest a peripheral lesion." So reads Gelb's rule number 4 in his description of the "Speed Play" approach to examination, in the first section of the book. A simple rule, but one the bewildered medical student will be grateful for. Of course, such rules may break down and then a more classic formulation is needed, as illustrated by Gelb's "Long Play" analysis. In this way, the student is shown how the practising neurologist really thinks through cases. Subsequent sections, on specific diseases or symptoms, are written by eight of Gelb's teaching colleagues at the University of Michigan. The advantage of this multiauthor approach is evident in the authoritative summaries of complex topical issues such as the genetics of the trinucleotide repeat disorders or familial Alzheimer's disease. But Gelb has coauthored each chapter and imposed a strict uniformity of style and approach, including the addition of useful illustrative case histories at the beginning of each chapter. Perhaps a few more figures or tables would have lightened the text, but otherwise I would strongly recommend this excellent little book to anyone who would like to steer more confidently through murky neurological waters.

ALASDAIR COLES 